\title{
Formaldehyde measurements by Proton transfer reaction - Mass Spectrometry (PTR-MS): correction for humidity effects
}

\author{
A. Vlasenko ${ }^{1,2, *}$, A .M. Macdonald ${ }^{2}$, S. J. Sjostedt ${ }^{1,2}$, and J. P. D. Abbatt ${ }^{1}$ \\ ${ }^{1}$ Department of Chemistry, University of Toronto, Toronto, Canada \\ ${ }^{2}$ Science and Technology Branch, Environment Canada, Toronto, Canada \\ *now at: Science and Technology Branch, Environment Canada, Toronto, Canada
}

Received: 25 February 2010 - Published in Atmos. Meas. Tech. Discuss.: 15 March 2010

Revised: 21 July 2010 - Accepted: 5 August 2010 - Published: 17 August 2010

\begin{abstract}
Formaldehyde measurements can provide useful information about photochemical activity in ambient air, given that $\mathrm{HCHO}$ is formed via numerous oxidation processes. Proton transfer reaction mass spectrometry (PTRMS) is an online technique that allows measurement of VOCs at the sub-ppbv level with good time resolution. PTRMS quantification of $\mathrm{HCHO}$ is hampered by the humidity dependence of the instrument sensitivity, with higher humidity leading to loss of PTR-MS signal. In this study we present an analytical, first principles approach to correct the PTRMS HCHO signal according to the concentration of water vapor in sampled air. The results of the correction are validated by comparison of the PTR-MS results to those from a Hantzsch fluorescence monitor which does not have the same humidity dependence. Results are presented for an intercomparison made during a field campaign in rural Ontario at Environment Canada's Centre for Atmospheric Research Experiments.
\end{abstract}

\section{Introduction}

Formaldehyde (HCHO) is an important atmospheric constituent that can be emitted directly or produced in-situ via oxidation of hydrocarbons. It is one of the most abundant oxygenated volatile carbonyls in the boundary layer with mixing ratios from $\sim 100 \mathrm{ppt}$ in polar pristine regions (Hutterli et al., 1999; Riedel et al., 1999; Sumner et al., 2002) up to $10-50 \mathrm{ppb}$ in polluted urban environments (Dasgupta et al., 2005; Garcia et al., 2006; Grosjean, 1991). The primary gas-phase atmospheric sinks for $\mathrm{HCHO}$ are reaction with $\mathrm{OH}$ and photolysis. Depending on the atmospheric conditions, the overall tropospheric $\mathrm{HCHO}$ lifetime is estimated

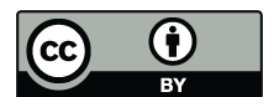

Correspondence to: A. Vlasenko (alexander.vlasenko@ec.gc.ca) to be only hours during the daytime, when the photolysis rate and $\mathrm{OH}$ concentration are at a maximum. The products of $\mathrm{HCHO}$ photolysis and $\mathrm{OH}$ reaction eventually produce the $\mathrm{HO}_{2}$ radical, which is an important atmospheric $\mathrm{HO}_{\mathrm{x}}$ constituent known to contribute to the formation of tropospheric ozone.

Several analytical techniques have been deployed to detect atmospheric $\mathrm{HCHO}$ including: cartridge collection followed by offline analysis (Grosjean and Fung, 1982), online gas to liquid trapping followed by derivatization and fluorescent detection (Kelly and Fortune, 1994), Fourier transform infrared spectroscopy FTIR (Tuazon et al., 1980), differential optical absorption spectroscopy DOAS (Lawson et al., 1990), multi-axes differential optical absorption spectroscopy MAX-DOAS (Heckel et al., 2005), tunable diode laser absorption spectroscopy TDL (Fried et al., 1998; Harris et al., 1989) and pulsed quantum cascade laser spectrometer QCL (Herndon et al., 2007). Recently, proton transfer mass spectrometry (PTR-MS) was used to measure ambient concentrations of HCHO (Karl et al., 2003; Steinbacher et al., 2004). The advantages of the PTR-MS technique include high time resolution and an ability to simultaneously detect a large number of VOC compounds (Lindinger et al., 1998), which could also be atmospheric $\mathrm{HCHO}$ precursors (e.g. isoprene, monoterpenes, ketones, etc).

Formaldehyde is detected with PTR-MS by monitoring the ion signal of $\mathrm{H} \cdot \mathrm{HCHO}^{+}$at $\mathrm{m} / z 31$ which is formed via Reaction (R1). Thermodynamically, this proton transfer is favourable since the proton affinity (PA) of $\mathrm{HCHO}$ $(170.4 \mathrm{kcal} / \mathrm{mol})$ is higher than that of water $(165.2 \mathrm{kcal} / \mathrm{mol})$ (Hunter and Lias, 2005).

$\mathrm{HCHO}+\mathrm{H}_{3} \mathrm{O}^{+} \rightarrow \mathrm{H} \cdot \mathrm{HCHO}^{+}+\mathrm{H}_{2} \mathrm{O}$

$\mathrm{H} \cdot \mathrm{HCHO}^{+}+\mathrm{H}_{2} \mathrm{O} \rightarrow \mathrm{HCHO}+\mathrm{H}_{3} \mathrm{O}^{+}$

However, because the PA difference is sufficiently small, $<30 \mathrm{~kJ}$ (Španêl et al., 2004), the back reaction of protonated

Published by Copernicus Publications on behalf of the European Geosciences Union. 
HCHO with water (R1a) becomes relevant and reduces the sensitivity of detection. Hansel et al. (1997) investigated the kinetics of the $\mathrm{H}_{3} \mathrm{O}^{+}$proton-transfer reaction to $\mathrm{HCHO}$ including the back reaction in a selected-ion flow drift tube experiment (SIFDT). Several studies reported the humidity dependence of PTR-MS detection using comparison with other techniques. Generally, their results suggested a significant (a factor of 3 to 5) underestimate of HCHO concentrations by PTR-MS which can be improved by taking into account reaction R1a (Christian et al., 2004; Karl et al., 2003; Steinbacher et al., 2004). Good agreement was observed between HCHO concentrations measured by a specially modified PTR-MS (i.e. the water leakage from ion source was reduced by enhanced pump-down), Hantzsch monitors and DOAS methods during special VOC intercomparison chamber tests (Wisthaler et al., 2008). Another interesting approach to improve $\mathrm{HCHO}$ sensitivity was to remove water vapour from the air sample by a cold trap installed upstream of the PTR-MS inlet (Jobson and McCoskey, 2010). In a recent report, Inomata et al. (2008) suggested a method to correct the PTR-MS sensitivity with respect to sample air humidity assuming equilibrium between (R1) and (R1a) in the drift tube (Inomata et al., 2008). In the present study, we extend this approach and propose a correction that can be applied over a wider humidity range. The results are discussed by comparing ambient $\mathrm{HCHO}$ measurements by PTR-MS and the Hantzsch monitor.

\section{Experimental}

\subsection{PTR-MS instrument}

The instrument used in this study was acquired from Ionicon Analytik GmbH (Innsbruck, Austria). A detailed description of the measurement principle and performance is given elsewhere (de Gouw and Warneke, 2007). Briefly, the instrument consists of an ion source, a drift-tube reaction chamber and a quadrupole mass spectrometer (QMS) (Balzers QMG422). $\mathrm{H}_{3} \mathrm{O}^{+}$ions are generated in the hollow cathode discharge from pure water vapour flowing at $6 \mathrm{sccm}$. Most of this vapour is pumped away by a turbo pump immediately after leaving the ion source, and only a small fraction escapes to the drift-tube. Sample flow $(25 \mathrm{sccm})$ is introduced at the entrance of the drift-tube, where $\mathrm{H}_{3} \mathrm{O}^{+}+$VOC ion-molecule reactions take place. During this study the drift tube was operated at 2.13 mbar pressure and the electric field was maintained at $600 \mathrm{~V}$ difference. The value for $\mathrm{E} / \mathrm{N}$ (E being the electric field strength and $\mathrm{n}$ the air density inside drift tube) in the drift tube is kept at about 135 Townsend (Td). The electrical field maintains a controlled ion velocity in the drifttube, which reduces the clustering of water ions as shown in Reactions (R2) and (R3):

$$
\mathrm{H}_{3} \mathrm{O}^{+}+\mathrm{H}_{2} \mathrm{O} \leftrightarrow \mathrm{H}_{3} \mathrm{O}^{+} \cdot \mathrm{H}_{2} \mathrm{O}
$$

$$
\mathrm{H}_{3} \mathrm{O}^{+} \cdot\left(\mathrm{H}_{2} \mathrm{O}\right)_{\mathrm{n}}+\mathrm{H}_{2} \mathrm{O} \leftrightarrow \mathrm{H}_{3} \mathrm{O}^{+} \cdot\left(\mathrm{H}_{2} \mathrm{O}\right)_{\mathrm{n}+1}
$$

The drift voltage also determines the ion reaction time $t$, which is calculated to be $9 \times 10^{-5} \mathrm{~s}$ for our system. The PTRMS inlet system and the drift-tube were maintained at $50^{\circ} \mathrm{C}$ to minimise wall losses. At the end of the drift tube the ions are extracted through a collision dissociation chamber into the QMS where they are detected by a secondary electronic multiplier (MasCom $\mathrm{GmbH}$ ).

\subsection{Hantzsch monitor}

The mixing ratio of $\mathrm{HCHO}$ was measured continuously using an instrument built in-house (Macdonald et al., 2001) based on a fluorescence technique similar to the Hantzsch monitor (Kelly and Fortune, 1994). HCHO was stripped from the air into a $\mathrm{H}_{2} \mathrm{SO}_{4}$ aqueous solution in a 28-turn glass coil with a liquid flow of $0.8 \mathrm{~mL} \cdot \mathrm{min}^{-1}$ and airflow of $2 \mathrm{~L} \cdot \mathrm{min}^{-1}$. The dissolved HCHO was then reacted with a ketone $(2,4-$ pentanedione, $0.01 \mathrm{M}$ ) in a solution of $6 \mathrm{M}$ ammonium acetate and $0.16 \mathrm{M}$ acetic acid. The ammonium acetate is both a source of ammonia for the reaction and a buffering agent. Formation of the reaction product, 3,5-diacetyl 1,4dihydrolutidine (DDL), took place in a reaction coil, heated to $80^{\circ} \mathrm{C}$, with a residence time of $30 \mathrm{~s}$. The DDL product was measured with a fluorescence detector (GTI/Spectrovision model FD-100) with a Xenon flash lamp, a $254 \mathrm{~nm}$ interference filter in the excitation path, and a combination of GG 19 and GG 435 Schott glass filters in the emission path. The instrument lag time was about $180 \mathrm{~s}$, and the response time was $90 \mathrm{~s}$. The instrument was calibrated daily with liquid standards, which varied by less than 5\% over the study period. A permeation-dilution system containing $\alpha$-polyoxymethylene $(\alpha$-POM) was also used to provide gas-phase standards. The permeation rate was determined gravimetrically over a threemonth period. Zero measurements were done hourly by diverting the ambient air through a cartridge packed with charcoal and molecular sieve. The limit of detection was defined as 3 times the standard deviation of the instrument zeros and was approximately $200 \mathrm{pptv}$. The instrument performance was tested during an intensive $\mathrm{HCHO}$ intercomparison campaign and very good agreement was found with TDL systems for variable atmospheric conditions (Macdonald et al., 1999).

\subsection{Laboratory experiments}

Two types of laboratory experiments were performed to study the signal response of the PTR-MS measurement at $\mathrm{m} / \mathrm{z} 31$ with a controlled known mixing ratio of $\mathrm{HCHO}$. In the first experiment the mixing ratios of $\mathrm{HCHO}$ were calculated from PTR-MS signals using such parameters as reaction rate constant, reaction time, and ion transmission and were compared to the mixing ratios prepared by flow dilution. Three different mixing ratios of $\mathrm{HCHO}$ were prepared using a permeation-dilution system comprised of a permeation source (VICI Metronics Inc.) and mass flow controllers 
(MKS). Synthetic air passed over the permeation tube, containing $\alpha$-polyoxymethylene (permeation rate $52.6 \mathrm{ng} / \mathrm{min}$ at $70^{\circ} \mathrm{C}$ ) at $1 \mathrm{~L} \cdot \mathrm{min}^{-1}$. This flow was diluted by another flow from a mass flow controller (MKS), and then was sampled simultaneously by the Hantzsch monitor and PTR-MS.

In the second type of experiment, the PTR-MS response was studied as a function of water vapour concentration in the sampling flow. A constant mixing ratio of $\mathrm{HCHO}$ was provided using the same permeation source kept at constant temperature and $1 \mathrm{~L} \cdot \mathrm{min}^{-1}$ flow of nitrogen. This flow was diluted by $1 \mathrm{~L} \cdot \mathrm{min}^{-1}$ humidified nitrogen flow which passed through a fritted bubbler containing deionised water. The bubbler was held in a constant temperature water bath. The humidified flow was saturated with respect to water which was tested by reducing the flow through the bubbler. By changing the temperature of the bubbler it was possible to keep all flows constant and vary the mixing ratio of water vapour in the sample flow from 3 to $21 \mathrm{mmol} / \mathrm{mol}$ in order to cover the range relevant to atmospheric conditions. The concentration of water vapour was calculated using the literature (Haar et al., 1984) and the flow dilution ratio. The calculated values were in excellent agreement (within $2 \%$ ) with data measured by a hygrometer (VWR International, accuracy $\pm 1 \%$ ) installed downstream of the flow mixing point.

\subsection{Field measurement}

Field measurements were made at the Environment Canada Centre for Atmospheric Research Experiments (CARE: $44.23 \mathrm{~N}, 79.78 \mathrm{~W}$; $251 \mathrm{~m}$ a.s.l.) in Egbert, Ontario. The details of the measurement location are published elsewhere (Vlasenko et al., 2009) so here we present only a brief summary. CARE is located in a rural area consisting of mixed forest and farmland, located about $70 \mathrm{~km}$ north of Toronto. There are minimal local pollution sources and the prevailing winds are commonly from the northwest, in which case the air can be exceedingly clean having its source in Northwestern Ontario and the Upper Great Lakes region. With south/southwesterly flow, the air comes from Toronto and Southern Ontario, a large metropolitan and industrial region of close to 8 million people. Measurements were made from 14 May to 15 June 2007. Inlets were located approximately $1 \mathrm{~m}$ above the roof of a sampling building and ambient air was sampled through a $7.5 \mathrm{~m}$ long PFA tube with $0.6 \mathrm{~cm}$ outer diameter. For the PTR-MS, a total inlet flow of $4.4 \mathrm{lpm}$ flow was pulled with a diaphragm pump, restricted by a needle valve. The residence time in the inlet line is $1.3 \mathrm{~s}$. The PTR-MS sampled part of the main flow $(200 \mathrm{sccm})$ through a heated $0.2 \mathrm{~cm}$ OD silcosteel line. Instrument background checks were performed regularly (14 times) by installing a charcoal cartridge (Supelco) upstream of the PTR-MS inlet line. Data presented in this paper were deduced by linearly interpolating the charcoal backgrounds from point to point. The inlet for the Hantzsch monitor also employed an inlet line filter with 5 micron pore size.

\section{Results and discussion}

A kinetic treatment is introduced to describe the ionmolecule reactions of $\mathrm{HCHO}, \mathrm{H}_{3} \mathrm{O}^{+}$and $\mathrm{H}_{2} \mathrm{O}$ in the drift tube. Then an approach is presented to determine the concentration of water in the drift tube originating from the ion source. The results of HCHO PTR-MS laboratory measurements are compared to the data from Hantzsch monitor for dry conditions. Finally, the results of the field intercomparison are discussed.

\subsection{Drift tube kinetics}

The kinetics of HCHO protonation (R1) and deprotonation (R1a) in the drift tube can be solved analytically using the assumption of constant concentrations of $\mathrm{H}_{2} \mathrm{O}$ and $\mathrm{H}_{3} \mathrm{O}^{+}$. Our main focus is the effect of water vapour so we neglect ion losses in the drift tube. The concentration of protonated $\mathrm{HCHO}$ ions at a given reaction time $t$ is as following, a standard expression for the kinetics of both forward and reverse reactions of the same process:

$$
\left[\mathrm{H}^{+} \cdot \mathrm{HCHO}\right]=\left[\mathrm{H}_{3} \mathrm{O}^{+}\right] \frac{k_{\mathrm{R} 1}[\mathrm{HCHO}]\left(1-\mathrm{e}^{-\left(k_{\mathrm{R} 1}[\mathrm{HCHO}]+k_{\mathrm{Rla}}\left[\mathrm{H}_{2} \mathrm{O}\right]\right) t}\right)}{k_{\mathrm{R} 1}[\mathrm{HCHO}]+k_{\mathrm{R} 1 \mathrm{a}}\left[\mathrm{H}_{2} \mathrm{O}\right]}
$$

$k_{\mathrm{R} 1}$ and $k_{\mathrm{R} 1 \mathrm{a}}$ are rate constants of Reactions (R1) and (R1a), respectively, and $[\mathrm{HCHO}],\left[\mathrm{H}_{3} \mathrm{O}^{+}\right]$and $\left[\mathrm{H}_{2} \mathrm{O}\right]$ are concentrations of $\mathrm{HCHO}$, hydronium ions and water in the drift tube.

Equation (1) can be simplified knowing that typical atmospheric conditions mixing ratios of $\mathrm{HCHO}$ are smaller than $10 \mathrm{ppb}$, and the ambient water vapor mixing ratio is higher than $0.1 \mathrm{mmol} / \mathrm{mol}$. In addition, the rate constants $k_{\mathrm{R} 1}=1.4 \times 10^{-9} \mathrm{~cm}^{3} / \mathrm{s}$ and $k_{\mathrm{R} 1 \mathrm{a}}=3 \times 10^{-11} \mathrm{~cm}^{3} / \mathrm{s}$ are known (Hansel et al., 1997). Then, $k_{\mathrm{R} 1 \mathrm{a}}\left[\mathrm{H}_{2} \mathrm{O}\right] \gg \mathrm{k}_{R 1}[\mathrm{HCHO}]$ and $k_{\mathrm{R} 1 \mathrm{a}}\left[\mathrm{H}_{2} \mathrm{O}\right]+k_{\mathrm{R} 1}[\mathrm{HCHO}] \approx k_{\mathrm{R} 1 \mathrm{a}}\left[\mathrm{H}_{2} \mathrm{O}\right]$ :

$$
\left[\mathrm{H}^{+} \cdot \mathrm{HCHO}\right]=\left[\mathrm{H}_{3} \mathrm{O}^{+}\right] \frac{k_{\mathrm{R} 1}[\mathrm{HCHO}]\left(1-\mathrm{e}^{-k_{\mathrm{R} 1 \mathrm{a}}\left[\mathrm{H}_{2} \mathrm{O}\right] \mathrm{t}}\right)}{k_{\mathrm{R} 1 \mathrm{a}}\left[\mathrm{H}_{2} \mathrm{O}\right]}
$$

It is worth noting that an equivalent equation has been proposed independently (Eq. 6 in Knighton et al., 2009) to explain the change in PTR-MS detection efficiency change with regard to humidity for $\mathrm{HCN}$, another VOC molecule which has a proton affinity similar to formaldehyde.

The sensitivity of the PTR-MS signal as a function of the water vapor concentration in the drift tube can be expressed by normalising the concentration of protonated $\mathrm{HCHO}$ to the signal at dry conditions $\left(\left[\mathrm{H}_{2} \mathrm{O}\right]_{\text {dry }}\right)$ when the concentration of water vapor in the drift tube is minimal:

$$
\frac{\left[\mathrm{H}^{+} \cdot \mathrm{HCHO}\right]}{\left[\mathrm{H}^{+} \cdot \mathrm{HCHO}\right]_{\mathrm{dry}}}=\frac{\left[\mathrm{H}_{2} \mathrm{O}\right]_{\mathrm{dry}}\left(1-\mathrm{e}^{-k_{\mathrm{Rla}}\left[\mathrm{H}_{2} \mathrm{O}\right] \mathrm{t}}\right)}{\left[\mathrm{H}_{2} \mathrm{O}\right]\left(1-\mathrm{e}^{-k_{\mathrm{Rla}}\left[\mathrm{H}_{2} \mathrm{O}\right]_{\mathrm{dry}} \mathrm{t}^{\mathrm{N}}}\right)} \approx \frac{\left(1-\mathrm{e}^{-k_{\mathrm{Rla}}\left[\mathrm{H}_{2} \mathrm{O}\right] \mathrm{t}}\right)}{\left[\mathrm{H}_{2} \mathrm{O}\right] k_{\mathrm{R} 1 \mathrm{a}} \mathrm{t}}
$$

Equation (3) is simplified using the fact that for most dry conditions observed experimentally the concentration of water molecules in the drift tube is $\left[\mathrm{H}_{2} \mathrm{O}\right]_{\text {dry }} \sim 1 \times 10^{13}$ molecules $/ \mathrm{cm}^{3}$ (This concentration corresponds to the case when sampling flow is water-free and 


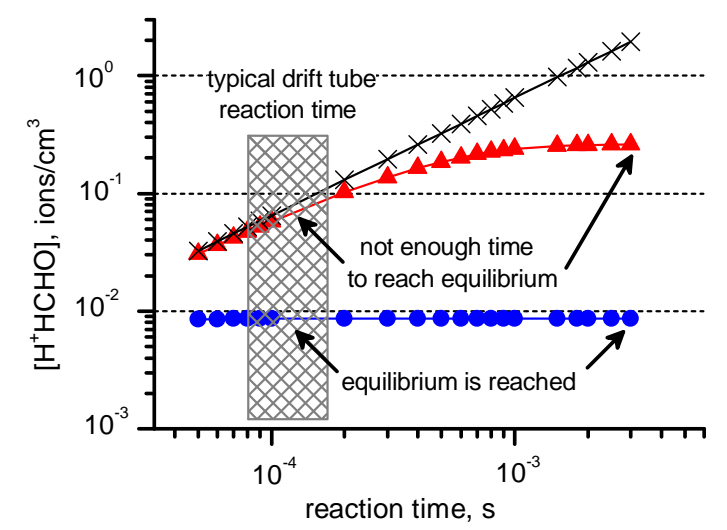

Fig. 1. Concentration of product ions $\mathrm{H}^{+} \cdot \mathrm{HCHO}$ as a function of reaction time for different scenarios. For all runs: [HCHO] $=5 \times 10^{7}$ molecules $/ \mathrm{cm}^{3},\left[\mathrm{H}_{3} \mathrm{O}^{+}\right]=1 \times 10^{4}$ ions $/ \mathrm{cm}^{3}$ (Steinbacher, 2004). Crosses correspond to the case when only the forward $\mathrm{R} 1$ reaction is considered and $k_{\mathrm{R} 1 \mathrm{a}}$ is set to zero. Circles $\left(\left[\mathrm{H}_{2} \mathrm{O}\right]=1.5 \times 10^{15}\right.$ molecules $\left./ \mathrm{cm}^{3}\right)$ and triangles $\left(\left[\mathrm{H}_{2} \mathrm{O}\right]=\right.$ $5 \times 10^{13}$ molecules $/ \mathrm{cm}^{3}$ ) correspond to the case where both the forward and reverse reactions, R1 and R1a, take place. Shaded area represents reaction times typical for the drift tube.

all $\mathrm{H}_{2} \mathrm{O}$ in the drift tube is originated from the ion source. See later discussion). In addition, the typical reaction time is $100 \mu$ s, so that $k_{\mathrm{R} 1 \mathrm{a}}\left[\mathrm{H}_{2} \mathrm{O}\right]_{\mathrm{dry}} \mathrm{t} \ll 1$ and thus, the exponent in the denominator can be expanded.

The sensitivity dependence to water in Eq. (3) is time dependent and differs from the one derived by (Inomata et al., 2008), who assumed R1 and R1a are at equilibrium. The time dependence becomes important under dry conditions when the concentration of water is lower and the equilibrium is not reached within typical reaction times. This effect is illustrated in Fig. 1 where the concentration of $\mathrm{H}^{+} \cdot \mathrm{HCHO}$ ions, calculated according to Eq. (2), is plotted as a function of time for two concentrations of water vapor in the drift tube. One sees that at higher $\mathrm{H}_{2} \mathrm{O}$ concentrations the production of $\mathrm{H}^{+}$. $\mathrm{HCHO}$ does not depend on reaction time. At a lower $\mathrm{H}_{2} \mathrm{O}$ concentration the equilibrium is reached only at times larger than $1 \times 10^{-3} \mathrm{~s}$ which is an order of magnitude higher than typical drift tube conditions. Also plotted is the concentration of $\mathrm{H}^{+} \cdot \mathrm{HCHO}$ ions when the reverse reaction, $\mathrm{R} 1 \mathrm{a}$, does not proceed. Overall, it is seen that the reaction system consisting of Reactions (R1) and (R1a) has kinetic constraints reaching equilibrium at lower $\left[\mathrm{H}_{2} \mathrm{O}\right]$.

Another illustration of how the sensitivity can be affected by $\mathrm{H}_{2} \mathrm{O}$ concentration is shown in Fig. 2. The calculated concentrations of $\mathrm{H}^{+} \cdot \mathrm{HCHO}$ ions (Eq. 1) are normalised by equilibrium values and plotted as a function of water partial pressure. For practical reasons the water amount is expressed in the $\mathrm{mmol} / \mathrm{mol}$ units corresponding to the levels in the sample flow. Modelling results suggest that equilibrium for $\mathrm{R} 1$ and R1a in the drift tube is reached for $\mathrm{H}_{2} \mathrm{O}$ mixing ratios higher that $10 \mathrm{mmol} / \mathrm{mol}$, which corresponds to drift

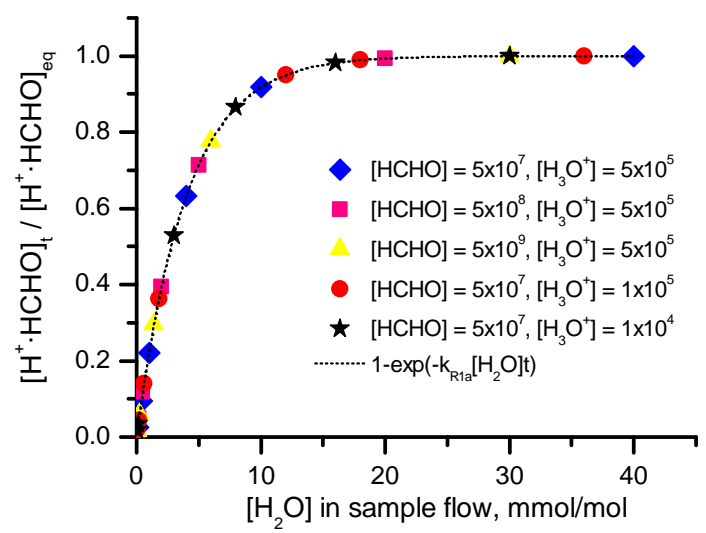

Fig. 2. Calculated concentration of $\mathrm{H}^{+} \cdot \mathrm{HCHO}$ ions normalized by corresponding equilibrium concentration shown as a function of water vapor amounts in the sample flow. Dotted line corresponds to the time dependent term in Eq. (2). Symbols correspond to calculations assuming various initial concentrations of $\mathrm{HCHO}$ and reagent ion in the drift tube. Reaction time is set to $1 \times 10^{-4} \mathrm{~s}$ in accord with drift tube reaction. Concentrations indicated in units of molecules $\mathrm{cm}^{-3}$ and reaction constant $k_{\mathrm{R} 1 \mathrm{a}}=6 \times 10^{-11} \mathrm{~cm}^{3} / \mathrm{s}$.

tube water concentration of $5 \times 10^{14}$ molecules $/ \mathrm{cm}^{3}$. Below this value the kinetic constraint should be considered. Different sets of initial conditions (concentrations of $\mathrm{HCHO}$ and $\mathrm{H}_{3} \mathrm{O}^{+}$) were used in the simulations as a sensitivity test, but no deviation from predicted behavior was observed.

Summarizing the results of the drift tube kinetic simulations, we conclude that for typical PTR-MS conditions there should be a strong water concentration dependence of $\mathrm{H}^{+} \cdot \mathrm{HCHO}$ ions produced in Reactions (R1) and (R1a). The equilibrium approach is not accurate for dry conditions and the PTR-MS signal at $\mathrm{m} / \mathrm{z} 31$ needs to be corrected taking into account the time dependent term in Eq. (3).

\subsection{Determination of water concentration in the drift tube originating from the ion source}

To account for the effect of water vapor in the drift tube it is necessary to know the $\mathrm{H}_{2} \mathrm{O}$ concentration. It was reported earlier (Inomata et al., 2008) that the total $\mathrm{H}_{2} \mathrm{O}$ concentration is a sum of water vapour that is entering the drift tube with the sample flow and also that emanating from the ion source: $\left[\mathrm{H}_{2} \mathrm{O}\right]_{\text {drifttube }}=\left[\mathrm{H}_{2} \mathrm{O}\right]_{\text {sample }}+\left[\mathrm{H}_{2} \mathrm{O}\right]_{\text {ion source. }}$. The contribution from the sample flow can be estimated by measuring the absolute humidity of sample air and adjusting for the pressure drop from ambient to drift tube conditions. $\left[\mathrm{H}_{2} \mathrm{O}\right]_{\text {ion source }}$ requires special attention because it was not measured directly during routine PTR-MS data acquisition.

To determine the concentration of water vapor in the drift tube that originates from the ion source we use the PTR-MS signal at $m / z 37$ which corresponds to the $\mathrm{H}_{3} \mathrm{O}^{+} \cdot \mathrm{H}_{2} \mathrm{O}$ cluster concentration. In particular, we fit field data for $m / z, 37$ as a function of humidity in the sample air with a second- 


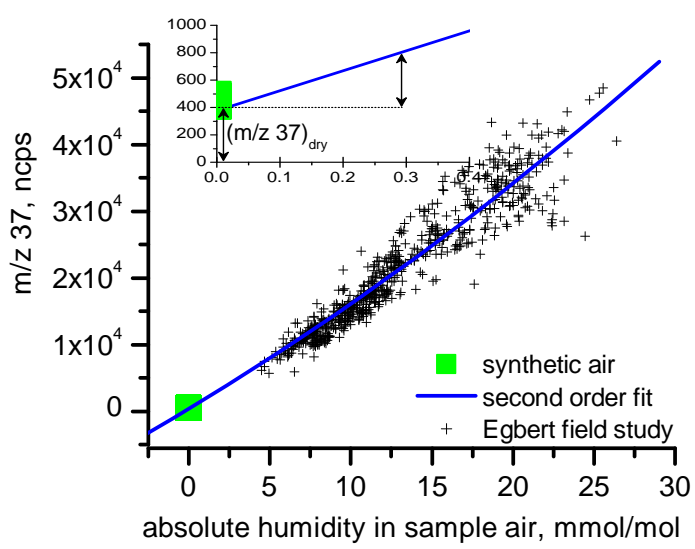

Fig. 3. Signal of $m / z, 37$ (units are normalized counts ncps signal, i.e. $\mathrm{m} / \mathrm{z}, 37$ normalized by $\mathrm{m} / \mathrm{z} 21)$ as a function of sample air absolute humidity. Crosses represent field data. Solid green box corresponds to synthetic air. The line is a second order regression fit $\mathrm{Y}=\mathrm{A}+\mathrm{B} 1 \times \mathrm{X}+\mathrm{B} 2 \times \mathrm{X}^{2}$ with the following parameters $\mathrm{A}=368$, $\mathrm{B} 1=1460, \mathrm{~B} 2=11$, with an $R^{2}=0.97$. The insert describes the manner by which the $\mathrm{H}_{2} \mathrm{O}$ concentration in the drift tube is estimated for the dry sample air condition.

order polynomial (Ammann et al., 2006). We then extrapolate to the condition when the sample flow is dry, where one estimates that the residual signal $\mathrm{m} / \mathrm{z} 37_{\mathrm{dry}} \approx 400 \mathrm{ncps}$ arises from $\left[\mathrm{H}_{2} \mathrm{O}\right]_{\text {ion source }}$ (see Fig. 3). We point out that the extrapolated value of the $\mathrm{m} / \mathrm{z} 37$ signal for dry conditions is in excellent agreement with the value measured in a separate experiment using synthetic air as a sample gas (shown as the green shaded region in the inset of Fig. 3 ). Assuming linear dependence of $m / z 37$ as a function of sample absolute humidity (Fig. 3 insert) we estimate that $\left[\mathrm{H}_{2} \mathrm{O}\right]_{\text {ion source }} \approx 0.3 \mathrm{mmol} / \mathrm{mol}$ expressed in units of humidity in sample air. The value of $0.3 \mathrm{mmol} / \mathrm{mol}$ humidity in the sample flow corresponds to $0.03 \%$ of total drift tube pressure.

The amount of water originating from the ion source of the PTR-MS used in this work is significantly smaller than that reported earlier for other instruments. For example, Ammann et al. (2006) published the range of normalized $\mathrm{m} / \mathrm{z} 37$ values of $3-5 \times 10^{4} \mathrm{ncps}$ and another value is $7 \times 10^{4} \mathrm{ncps}$ (de Gouw and Warneke, 2007). Smaller values, $\sim 1.5 \times 10^{4} \mathrm{ncps}$, can also be found in the literature (Inomata et al., 2008; Steinbacher et al., 2004) but these values are still a factor of three higher than observed in our study. Such a wide range of protonated water dimer concentrations for dry conditions can be explained by the difference in PTR-MS operation settings, namely drift tube pressure, voltage and temperature and so that the comparison of water dimer counts can be only considered as qualitative. The main reason for the very low $\left[\mathrm{H}_{2} \mathrm{O}\right]_{\text {ion source }}$ concentration for the PTR-MS used in this study is the recent change to the ion source downstream pumping made by the instrument manufacturer (A. Hansel, personal communication).

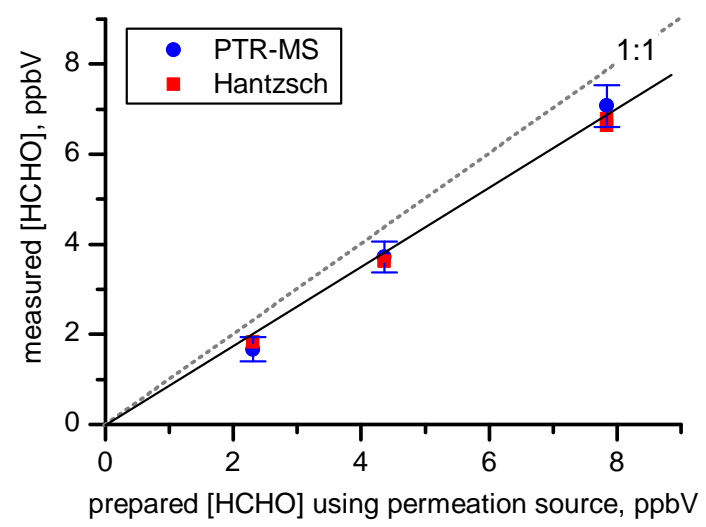

Fig. 4. Comparison of $\mathrm{HCHO}$ mixing ratio measurements by the PTR-MS and Hantzsch monitor using a permeation HCHO source and synthetic air as the carrier gas. The Hantzsch monitor HCHO mixing ratios are calculated using a liquid calibration standard (squares). PTR-MS mixing ratios are calculated from $\mathrm{m} / \mathrm{z} 31 \mathrm{sig}$ nal using Eq. (4) (circles).

\subsection{Comparison with Hantzsch monitor at dry conditions}

A starting point for comparison of the PTR-MS HCHO measurement with the Hantzsch monitor is under dry conditions when the influence of the backward reaction R1a is minimal. Using synthetic air as a buffer gas with addition of a known amount of HCHO, the response of the PTR-MS was measured. Under pseudo first-order conditions the signal at $m / z 31$ was then converted to $\mathrm{HCHO}$ mixing ratio with the assumption of negligible depletion of reagent $\mathrm{H}_{3} \mathrm{O}^{+}$:

$[\mathrm{HCHO}]_{\mathrm{ppb}} \approx \frac{1}{\mathrm{k}_{\mathrm{R} 1} \mathrm{t}} \frac{\mathrm{m} / \mathrm{z} 31 / \tau_{m / z 31}}{500 \mathrm{~m} / \mathrm{z} 21 / \tau_{m / z 21}} \frac{10^{9}}{\mathrm{~N}}$

where $m / z 31_{\text {background }}$ is signal measured in synthetic air; $k_{\mathrm{R} 1}=1.4 \times 10^{-9} \mathrm{~cm}^{3} / \mathrm{s} ; \tau_{m / z 31}$ and $\tau_{m / z 21}$ are transmission factors for $\mathrm{H}^{+} \cdot \mathrm{HCHO}$ and $\mathrm{H}_{3}^{18} \mathrm{O}^{+}$ions, respectively, and the factor 500 is used to account for the fact that the $\mathrm{H}_{3}^{18} \mathrm{O}^{+}$isotope is measured as the reagent ion instead of $\mathrm{H}_{3}^{16} \mathrm{O}^{+}$(count rate at $m / z, 19$ is too high to measure properly). For the calculation we used a literature value $\tau_{m / z 31} / \tau_{m / z 21}=1.4$ (Ammann et al., 2004) which is in good agreement (within 10\%) with the manufacturer's data for the particular instrument.

Figure 4 shows the results of $\mathrm{HCHO}$ mixing ratio calculations from the PTR-MS measurement compared to values detected by the Hantzsch monitor. While there is excellent agreement between both methods one sees that the measurements slightly (14\%) underestimate $\mathrm{HCHO}$ mixing ratios derived from the permeation source rate. A possible reason for that can be wall losses on the way from the HCHO source delivery to the instruments as well as instrumental collection efficiency issues: losses on silcosteel lines for PTR-MS and gas-to-liquid stripping efficiency for the Hantzsch monitor. 


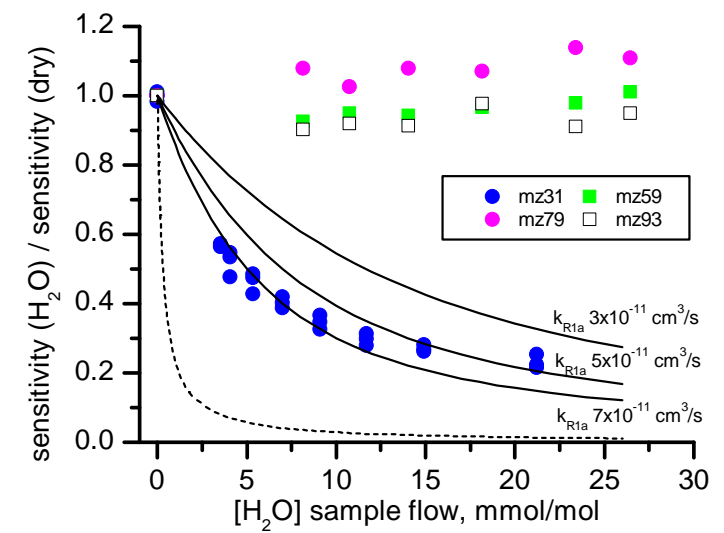

Fig. 5. Sensitivity of HCHO PTR-MS signal $\mathrm{m} / \mathrm{z} 31$ as a function of sample flow water amount. Data points for $m / z 59,79$ and 93 correspond to signals of acetone, benzene and toluene, respectively. Solid ines are the calculated dependence according to Eq. (3), using the labeled rate constants for the reverse reaction, R1a. Dashed line is the calculated dependence according to Eq. (5), representing equilibrium approach. Mixing ratios of formaldehyde, acetone, benzene, toluene are about 17, 10,10,10 ppbV, respectively.

\subsection{Laboratory experiment}

The influence of water on the measured and calculated response sensitivities to $\mathrm{HCHO}$ is given in Fig. 5. There is a significant drop of HCHO signal as a function of sample humidity. The data suggest that the best agreement between measurement and calculation is found for the backward reaction rate constant, $k_{\mathrm{R} 1 \mathrm{a}}$, between $5-7 \times 10^{-11} \mathrm{~cm}^{3} / \mathrm{s}$, about a factor of two higher than the literature value of $3 \times 10^{-11} \mathrm{~cm}^{3} / \mathrm{s}$. This is a small discrepancy, and could possibly be due to either an energy dependence in the rate constant, to uncertain reaction times, or, perhaps, to an error in the literature value. Also, we note that the model and measurements disagree most at high humidities, perhaps due to another process of $\mathrm{H}^{+} \mathrm{HCHO}$ formation taking place that is not accounted by the calculation. As humidity increases in the drift tube so does the concentration of protonated water dimers. The latter react with $\mathrm{HCHO}$ through ligand switching reactions and subsequent collisional dissociation of the organic water cluster (Jobson and McCoskey, 2010). If we assume that the dimer reaction rate is $75 \%$ that of $\mathrm{H}_{3} \mathrm{O}^{+}$ (Midey et al., 2000) and use the signal at $m / 237$ to estimate the dimer fraction relative to the monomer, we are able to explain a $6 \%$ difference between measurement and calculation at the highest humidity. Nevertheless, even with these uncertainties, using a rate constant of $6 \times 10^{-11} \mathrm{~cm}^{3} / \mathrm{s}$ matches the observations to an accuracy of better than $20 \%$. Furthermore, the time-dependent approach seems to constrain experimental data much better than the correction based on the assumption of equilibrium between Reactions (R1) and (R1a). Using terms from Inomata et al. (2008) one may define the follow-

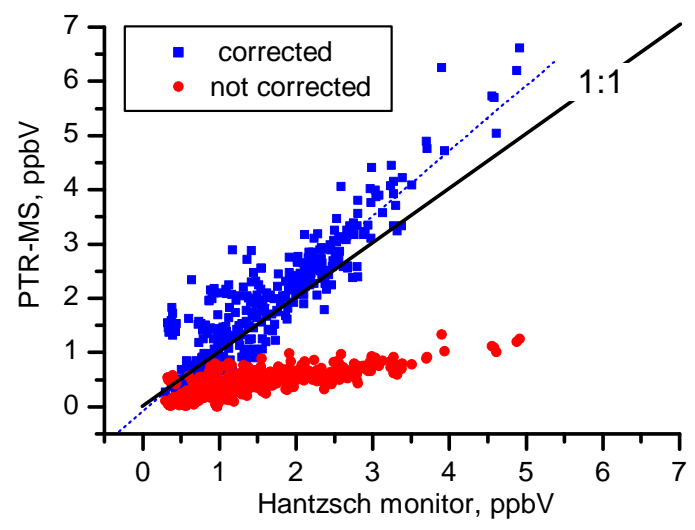

Fig. 6. Intercomparison of formaldehyde detection by PTR-MS and the Hantzsch monitor for the Egbert 2007 dataset. Humidity correction of PTR-MS data was done using reaction constant $k_{\mathrm{R} 1 \mathrm{a}}=6 \times 10^{-11} \mathrm{~cm}^{3} / \mathrm{s}$.

ing relationship for $\mathrm{m} / \mathrm{z} 31$ sensitivity decrease as a function of water vapour in sample:

$$
\frac{\left[\mathrm{H}^{+} \cdot \mathrm{HCHO}\right]}{\left[\mathrm{H}^{+} \cdot \mathrm{HCHO}\right]_{\mathrm{dry}}}=\frac{\left[\mathrm{H}_{2} \mathrm{O}\right]_{\mathrm{dry}}}{\left[\mathrm{H}_{2} \mathrm{O}\right]+\left[\mathrm{H}_{2} \mathrm{O}\right]_{\mathrm{dry}}}
$$

Since the value of $\left[\mathrm{H}_{2} \mathrm{O}\right]_{\text {dry }}$ for particular PTR-MS system was determined earlier (3.2) we may calculate the sensitivity dependence. The result is given in Fig. 5 and apparently there is a significant deviation from experimental data.

As a reference, the PTR-MS response is shown for other VOC species - toluene, benzene and acetone. There is little change with regard to humidity change for all compounds. This result is different from literature data (Warneke et al., 2001) where a significant decrease of the PTR-MS signal for aromatics (especially for toluene) was found as a result of $\mathrm{H}_{3} \mathrm{O}^{+}$reagent ion decrease at higher humidity. The results for acetone however are in agreement - the mass spectrometer signal at $m / 259$ is not affected significantly as humidity changes in the sample flow.

\subsection{Field study intercomparison}

The formaldehyde mixing ratio was calculated from the PTR-MS signal and compared to data measured by the Hantzsch monitor (Fig. 6). One approach, defined as not corrected, was to apply a single response factor of $8.5 \mathrm{ncps} / \mathrm{ppb}$ (i.e. see Fig. $4 ; \mathrm{m} / \mathrm{z} 31_{\text {background }}$ signal was interpolated between charcoal measurements) for the whole field study dataset. A second approach was to correct the data for the humidity dependent sensitivity (Eq. 3) based on the kinetics parameters determined in laboratory experiments. The concentration of water vapour in the sample flow was calculated from the measurements of air relative humidity and ambient temperature. The humidity corrected data agree much better with the Hantzsch measurement, with a linear slope only 
$5 \%$ higher that the 1:1 line. This is a small overestimate that might possibly be due to contribution of methyl hydroperoxide (MHP) $\mathrm{CH}_{3} \mathrm{OOH}$, which has been suggested as an interference at $\mathrm{m} / \mathrm{z} 31$ (Inomata et al., 2008). Median measured concentrations of MHP have ranged from $1.1 \mathrm{ppbV}$ in Korea (Hong et al., 2008) to (0.18 ppbV) in Antarctica (Frey et al., 2009). Another potential interference can be hydroxymethyl hydroperoxide $\mathrm{CH}_{2} \mathrm{OHOOH}$, which might decompose in the stripping solution to give HCHO and affect Hantzsch measurement results. The quantitative estimates of these contributions, however, was not studied in this work. The influence of other interferences, such as those resulting from fragmentation of protonated methanol and formic acid is believed to be small. For example, no interference from methanol was found when it was introduced from a calibration standard we have used in our lab.

\section{Conclusions}

We conclude by noting that laboratory, field and modeling studies all show that PTR-MS detection of formaldehyde at $\mathrm{m} / \mathrm{z} 31$ is strongly dependent on ambient water vapor concentration. With the help of kinetic modelling, it is shown that the assumption of equilibrium for the water-formaldehyde ion cluster system is limited for higher sample air humidities. In particular for the conditions described in this study, the equilibrium approach cannot be used when humidity is less than $15 \mathrm{mmol} / \mathrm{mol}$. And so, we propose an analytic, timedependent correction to be used to correct the PTR-MS signal at $\mathrm{m} / \mathrm{z} 31$ in order to obtain the absolute concentration of formaldehyde in the ambient sample. Based on the results of a field study, agreement to within 5\% is found between PTRMS corrected data and the Hantzsch monitor data for $\mathrm{HCHO}$ mixing ratios ranging from about 0.5 to $5 \mathrm{ppb}$. This indicates that the accuracy of the correction approach is very good. However we do note that considerable scatter in the PTRMS - Hantzsch intercomparison arises for mixing ratios below about $1.5 \mathrm{ppb}$, and it is unclear whether this arises from only one experimental method or a combination of the two. At this point, this scatter limits the accuracy to which mixing ratios can be reported from this PTR-MS approach in field settings. Future studies would be warranted with intercomparison to an alternate selective $\mathrm{HCHO}$ measurement method to test this PTR-MS correction approach to lower mixing ratios.

Acknowledgements. We acknowledge funding from the Canadian Foundation for Climate and Atmospheric Sciences, through the CAFC Network, and from NSERC. The project has also received funding support from the Ontario Ministry of the Environment. Such support does not indicate endorsement by the Ministry of the contents of this material. At Environment Canada we are grateful to the support of Richard Leaitch and Art Tham. We have had useful comments and discussions with Armin Hansel and Armin Wisthaler from University of Innsbruck, Satoshi Inomata from
National Institute for Environmental Studies, and Berk Knighton from Montana State University. We also thank anonymous referees for their helpful comments on the initial manuscript.

Edited by: E. C. Apel

\section{References}

Ammann, C., Spirig, C., Neftel, A., Steinbacher, M., Komenda, M., and Schaub, A.: Application of PTR-MS fro measurements of biogenic VOC in a deciduous forest, Int. J. Mass Spectrom., 239, 87-101, 2004.

Ammann, C., Brunner, A., Spirig, C., and Neftel, A.: Technical note: Water vapour concentration and flux measurements with PTR-MS, Atmos. Chem. Phys., 6, 4643-4651, doi:10.5194/acp6-4643-2006, 2006.

Christian, T. J., Kleiss, B., Yokelson, R. J., Holzinger, R., Crutzen, P. J., Hao, W. M., Shirai, T., and Blake, D. R.: Comprehensive laboratory measurements of biomassburning emissions: 2. First intercomparison of open-path FTIR PTR-MS, and GC- MS/FID/ECD, J. Geophys. Res., 109, doi:10.1029/2003JD003874, 2004.

Dasgupta, P. K., Li, J. Z., Zhang, G. F., Luke, W. T., McClenny, W. A., Stutz, J., and Fried, A.: Summertime ambient formaldehyde in five US metropolitan areas: Nashville, Atlanta, Houston, Philadelphia, and Tampa, Environ. Sci. Technol., 39, 4767-4783, 2005.

de Gouw, J. and Warneke, C.: Measurements of volatile organic compounds in the earths atmosphere using proton-transferreaction mass spectrometry, Mass Spectrom. Rev., 26, 223-257, 2007.

Frey, M. M., Hutterli, M. A., Chen, G., Sjostedt, S. J., Burkhart, J. F., Friel, D. K., and Bales, R. C.: Contrasting atmospheric boundary layer chemistry of methylhydroperoxide $(\mathrm{CH} 3 \mathrm{OOH})$ and hydrogen peroxide $\left(\mathrm{H}_{2} \mathrm{O}_{2}\right)$ above polar snow, Atmos. Chem. Phys., 9, 3261-3276, doi:10.5194/acp-9-3261-2009, 2009.

Fried, A., Henry, B., Wert, B., Sewell, S., and Drummond, J. R.: Laboratory, ground-based, and airborne tunable diode laser systems: performance characteristics and applications in atmospheric studies, Appl. Phys. B-Lasers Opt., 67, 317-330, 1998.

Garcia, A. R., Volkamer, R., Molina, L. T., Molina, M. J., Samuelson, J., Mellqvist, J., Galle, B., Herndon, S. C., and Kolb, C. E.: Separation of emitted and photochemical formaldehyde in Mexico City using a statistical analysis and a new pair of gas-phase tracers, Atmos. Chem. Phys., 6, 4545-4557, doi:10.5194/acp-64545-2006, 2006.

Grosjean, D. and Fung, K.: Collection efficiencies of cartridges and microimpingers for sampling of aldehydes in air as 2,4 dinitrophenylhydrazones, Anal. Chem., 54, 1221-1224, 1982.

Grosjean, D.: Ambient levels of formaldehyde, acetaldehyde, and formic acid in Southern California: Results of a one-year baseline study, Environ. Sci. Technol., 25, 710-715, 1991.

Haar, L., Gallagher, J. S., and Kell, G. S.: NBS/NRC Steam Tables, Hemisphere Publishing Corp., New York, 1984.

Hansel, A., Singer, W., Wisthaler, A., Schwarzmann, M., and Lindinger, W.: Energy dependencies of the proton transfer reactions $\mathrm{H}_{3} \mathrm{O}^{+}+\mathrm{CH}_{2} \mathrm{O} \leftrightarrow \mathrm{CH}_{2} \mathrm{OH}^{+}+\mathrm{H}_{2} \mathrm{O}$, Int. J. Mass Spectrom., 167, 697-703, 1997. 
Harris, G. W., Mackay, G. I., Iguchi, T., Mayne, L. K., and Schiff, H. I.: Measurements of Formaldehyde in the Troposphere by Tunable Diode-Laser Absorption-Spectroscopy, J. Atmos. Chem., 8, 119-137, 1989.

Heckel, A., Richter, A., Tarsu, T., Wittrock, F., Hak, C., Pundt, I., Junkermann, W., and Burrows, J. P.: MAX-DOAS measurements of formaldehyde in the Po-Valley, Atmos. Chem. Phys., 5, 909918, doi:10.5194/acp-5-909-2005, 2005.

Herndon, S. C., Zahniser, M. S., Nelson, D. D., Jr., Shorter, J., McManus, J. B., Jiménez, R., Warneke, C., and de Gouw, J. A.: Airborne measurements of $\mathrm{HCHO}$ and $\mathrm{HCOOH}$ during the New England Air Quality Study 2004 using a pulsed quantum cascade laser spectrometer, J. Geophys. Res., 112, doi:10.1029/2006JD007600, 2007.

Hong, S. B., Kim, G. S., Kang, C. H., and Lee, J. H.: Measurement of ambient hydroperoxides using an automated HPLC system and various factors which affect variations of their concentrations in Korea, Environ. Monit. Assess., 147, 23-34, 2008.

Hunter, E. P. and Lias, S. G.: Proton Affinity Evaluation, in: NIST Chemistry WebBook, NIST Standard Reference Database Number 69, edited by: Mallard, P. J. L. a. W. G., National Institute of Standards and Technology, Gaithersburg MD, 20899 (http://webbook.nist.gov), 2005.

Hutterli, M. A., Rothlisberger, R., and Bales, R. C.: Atmosphereto-snow-to-firn transfer studies of HCHO at Summit, Greenland, Geophys. Res. Lett., 26, 1691-1694, 1999.

Inomata, S., Tanimoto, H., Kameyama, S., Tsunogai, U., Irie, H., Kanaya, Y., and Wang, Z.: Technical Note: Determination of formaldehyde mixing ratios in air with PTR-MS: laboratory experiments and field measurements, Atmos. Chem. Phys., 8, 273284, doi:10.5194/acp-8-273-2008, 2008.

Jobson, B. T. and McCoskey, J. K.: Sample drying to improve $\mathrm{HCHO}$ measurements by PTR-MS instruments: laboratory and field measurements, Atmos. Chem. Phys., 10, 1821-1835, doi:10.5194/acp-10-1821-2010, 2010.

Karl, T., Jobson, T., Kuster, W. C., Williams, E., Stutz, J., Shetter, R., Hall, S. R., Goldan, P., Fehsenfeld, F., and Lindinger, W.: Use of proton-transfer-reaction mass spectrometry to characterize volatile organic compound sources at the La Porte super site during the Texas Air Quality Study 2000, J. Geophys. Res., 108, doi:10.1029/2002JD003333, 2003.

Kelly, T. J. and Fortune, C. R.: Continuous Monitoring of Gaseous Formaldehyde Using an Improved Fluorescence Approach, Int. J. Environ. Anal. Chem., 54, 249-263, 1994.

Knighton, W. B., Fortner, E. C., Midey, A. J., Viggiano, A. A., Herndon, S. C., Wood, E. C., and Kolb, C. E.: HCN detection with a proton transfer reaction mass spectrometer, Int. J. Mass Spectrom., 283, 112-121, 2009.

Lawson, D. R., Biermann, H. W., Tuazon, E. C., Winer Mackay, A. M. G. I., Schiff, H. I., Kok, G. L., Dasgupta, P. K., and Fung, K.: Formaldehyde measurement methods evaluation and ambient concentrations during the Carbonaceous Species Methods Comparison Study, Aerosol Sci. Technol., 12, 64-76, 1990.

Lindinger, W., Hansel, A., and Jordan, A.: On-line monitoring of volatile organic compounds at pptv levels by means of protontransfer-reaction mass spectrometry (PTR-MS) - Medical applications, food control and environmental research, Int. J. Mass Spectrom., 173, 191-241, 1998.
Macdonald, A. M., Wiebe, H. A., Li, S. M., Dryfhout-Clark, H., Asalian, K., Lu, G., Wang, D., Schiller, C. L., Harris, G. W., Sumner, A. L., and Shepson, P. B.: Results of a Formaldehyde Intercomparison Study in Ontario, Atmospheric Environment Service, Environment Canada, Toronto, ACSD-99-001, 1999.

Macdonald, A. M., Makar, P. A., Anlauf, K. G., Hayden, K. L., Bottenheim, J. W., Wang, D., and Dann, T.: Summertime formaldehyde at a high-elevation site in Quebec, J. Geophys. Res., 106, 32361-32374, 2001.

Midey, A. J., Arnold, S. T., and Viggiano, A. A.: Reactions of $\mathrm{H} 3 \mathrm{O}+(\mathrm{H} 2 \mathrm{O})(\mathrm{n})$ with formaldehyde and acetaldehyde, J. Phys. Chem. A, 104, 2706-2709, 2000.

Riedel, K., Weller, R., and Schrems, O.: Variability of formaldehyde in the Antarctic troposphere, Phys. Chem. Chem. Phys., 1, 5523-5527, 1999.

Španêl, P., Wang, T., and Smith, D.: Quantification of hydrogen cyanide in humid air by selected ion flow tube mass spectrometry, Rapid Commun. Mass Spectrom., 18, 1869-1873, 2004.

Steinbacher, M.: Volatile Organic Compounds and Their Oxidation Products in the Atmospheric Boundary Layer: Laboratory and Field Measurements, PhD Thesis Nr. 15557, Naturwissenschaften, ETH, Zürich, 151 pp., 2004.

Steinbacher, M., Dommen, J., Ammann, C., Spirig, C., Neftel, A., and Prevot, A. S. H.: Performance characteristics of a protontransfer-reaction mass spectrometer (PTR-MS) derived from laboratory and field measurements, Int. J. Mass Spectrom., 239, 117-128, 2004.

Sumner, A. L., Shepson, P. B., Grannas, A. M., Bottenheim, J. W., Anlauf, K. G., Worthy, D., Schroeder, W. H., Steffen, A., Dominé, F., Perrier, S., and Houdier, S.: Atmospheric chemistry of formaldehyde in the Arctic troposphere at Polar Sunrise, and the influence of the snowpack, Atmos. Environ., 36, 2553-2562, 2002.

Tuazon, E. C., Winer, A. M., Graham, R. A., and Pitts, Jr., J. N.: Atmospheric measurements of trace pollutants by kilometerpathlength FT-IR spectroscopy, Adv. Environ. Sci. Technol., 10, 259-300, 1980.

Vlasenko, A., Slowik, J. G., Bottenheim, J. W., Brickell, P. C., Chang, R. Y. W., Macdonald, A. M., Shantz, N. C., Sjostedt, S. J., Wiebe, H. A., Leaitch, W. R., and Abbatt, J. P. D.: Measurements of VOCs by proton transfer reaction mass spectrometry at a rural Ontario site: Sources and correlation to aerosol composition, J. Geophys. Res., 114, doi:10.1029/2009JD012025, 2009.

Warneke, C., van der Veen, C., Luxembourg, S., de Gouw, J. A., and Kok, A.: Measurements of benzene and toluene in ambient air using proton-transfer-reaction mass spectrometry: calibration, humidity dependence, and field intercomparison, Int. J. Mass Spectrom., 207, 167-182, 2001.

Wisthaler, A., Apel, E. C., Bossmeyer, J., Hansel, A., Junkermann, W., Koppmann, R., Meier, R., Mller, K., Solomon, S. J., Steinbrecher, R., Tillmann, R., and Brauers, T.: Technical Note: Intercomparison of formaldehyde measurements at the atmosphere simulation chamber SAPHIR, Atmos. Chem. Phys., 8, 21892200, doi:10.5194/acp-8-2189-2008, 2008. 